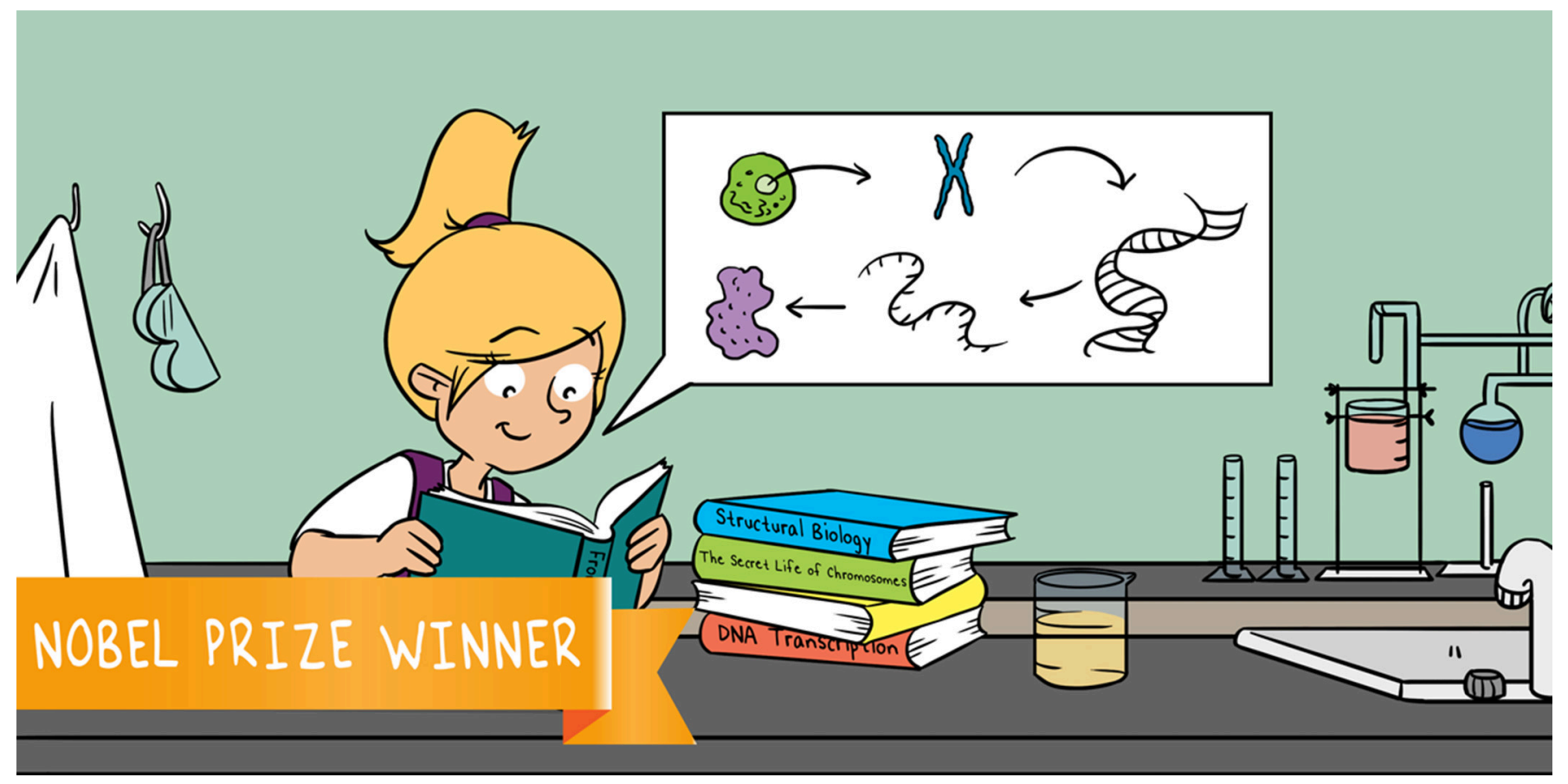

\title{
THE TRANSCRIPTION OF LIFE: FROM DNA TO RNA
}

\section{Roger D. Kornberg *}

Department of Structural Biology, Stanford University School of Medicine, Stanford, CA, United States

YOUNG REVIEWERS:

NATAN

ALTERMAN

ORT

JUNIOR

$\mathrm{HIGH}$

SCHOOL,

ISRAEL

AGES: $13-15$
In the last 50 years, I have dedicated my career to studying fundamental questions in biology. These questions address some of the most basic processes of life, such as "How do cells carrying the same genetic information differentiate into some 200 cell types in the human body?" and "How do cells remodel in response to environmental information?" In this article I will take you on a journey through some of my research into these questions. I will describe my main findings about DNA and its transcription to mRNA through a complex machinery called RNA polymerase II. mRNA is eventually translated into proteins that play a variety of major roles within the organism, including building cells, responding to environmental signals, accelerating chemical reactions, and transmitting signals between distant tissues. Last, I will share with you some fascinating open questions that we are now working on and close with a few tips for you-the scientists of the future. 
Figure 1

The cell's membrane and the nucleus containing the DNA. The cell is the basic unit of life. The nucleus, which is the information center of the cell, contains chromosomes. Each chromosome is an " $X$ "-shaped structure (red circle) that holds a portion of the DNA [Image source: Wikipedia (https://en.wikipedia.org/ wiki/Chromosome)].

\section{DEOXYRIBONUCLEIC} ACID (DNA)

The material that carries genetic information in living organisms. DNA is built from two strands in the form of a double helix and it is located inside the cell's nucleus.

\section{PROTEINS}

Large molecules, found in all living cells, which play many important roles in organisms.

\section{CHROMOSOME}

The basic structure into which the DNA is arranged inside the cell's nucleus.

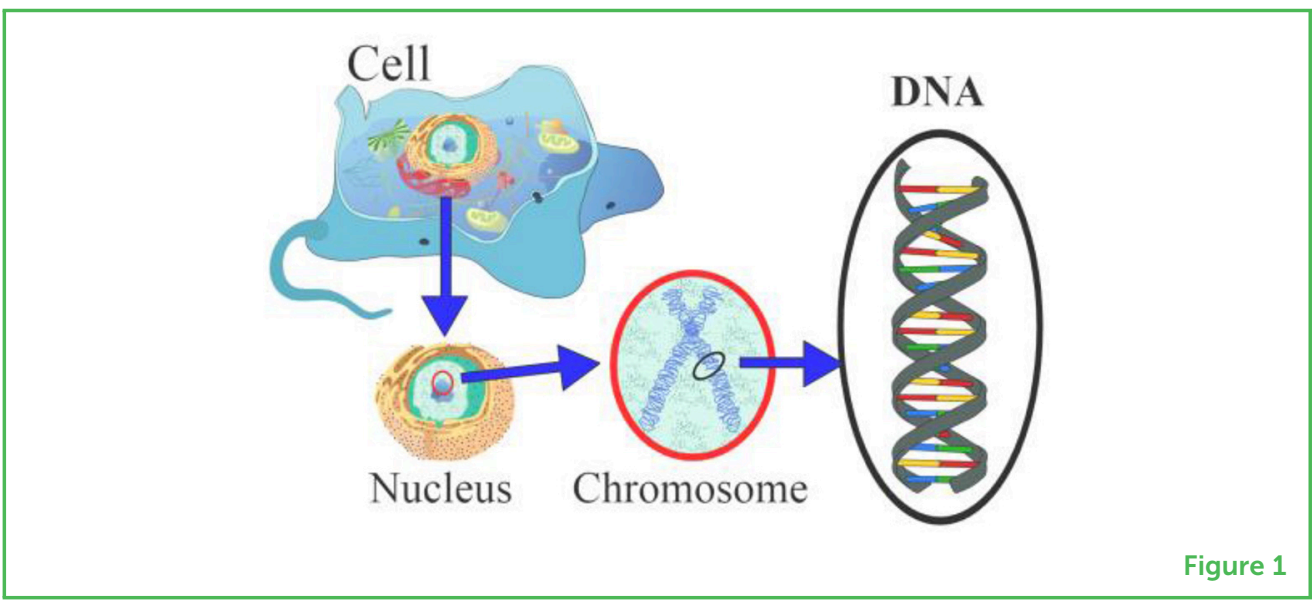

\section{MY WAY TO RNA}

My father was a biochemist and was awarded a Nobel prize in 1959 for his work on deoxyribonucleic acid (DNA) replication. He shared his immense enthusiasm for his research with anyone who would listen, and I absorbed his love for science. In college I studied mathematics, physics, and chemistry, and for my Ph.D. I did research on the dynamics of membranes (Figure 1, left). Membranes play the most fundamental role in life, because this envelope surrounding the living cell is what defines the existence of a cell-the basic unit of every living thing.

Toward the end of my work on membranes, I knew that I wanted to continue working on the physics and chemistry that relate to the life sciences. At that time, the field of structural biology, which is the study of cell components and processes, was rapidly growing. New technologies enabled the structures of simple proteins to be solved. I then became aware of the interesting problem of chromosome structure (see Figure 1). The chromosome is the structure in which our genetic material, the DNA, resides in all cells. Chromosome structure was intriguing for structural biologists because of DNA's fundamental importance and its seemingly simple structure. We already knew that the chromosomes are made up of DNA and an equal mass of four very small proteins. All we needed to figure out was how the DNA and the four proteins were arranged together to form the structure of the chromosome.

Well, it turned out that this problem was not at all simple. Eventually, I solved it by identifying the few relevant research papers among the many hundreds of them written on chromosome structure. These papers led me to the solution. I performed relevant experiments and put the pieces of the puzzle together and elucidated the structure of the chromosome. This structure was later proven to be correct by a technique called X-ray crystallography. 


\section{TRANSCRIPTION}

The first step in gene expression, in which a segment of the DNA is copied into an mRNA molecule.

MESSENGER RNA (mRNA)

A type of RNA that is involved in building proteins based on the information stored in the DNA.

\section{ENZYMES}

Large molecule that accelerate chemical reactions that take place in the body or inside the cell.

GENERAL TRANSCRIPTION FACTORS (GTFs)

A group of proteins that assist the initiation of DNA transcription to mRNA.

\section{MEDIATOR}

A multi-protein complex that processes information about gene regulation and transmits that information to the GTFs and RNA polymerase II.
After solving the structure of the chromosome, the next natural step was to investigate the implications of this structure for biology, for life itself. How does DNA, organized in this way inside the chromosome, engage in the expression of genetic information? Gene expression begins with a process called transcription, in which a messenger RNA (mRNA) molecule is formed from the DNA. The mRNA molecule is similar to the DNA molecule, but it has a different structure and function. Unlike the two strands from which DNA is made (Figure 1, right), the mRNA molecule is made of a single shorter strand, which is a copy of a particular segment of the DNA sequence. The mRNA serves as an intermediate, linking the genetic information coded in the DNA to the proteins that are eventually synthesized based on this information. To investigate the role of the chromosome in gene expression, I began by studying one of the three enzymes that participate in transcription. This enzyme is called RNA polymerase II [1].

\section{FROM DNA TO RNA-THE RNA POLYMERASE II TRANSCRIPTION MACHINERY}

The function of the RNA polymerase II transcription machinery is to create mRNA. As I mentioned above, mRNA serves as a link between the DNA code and the proteins that are produced from this code. The RNA polymerase II transcription machinery consists of almost 60 different proteins! I will describe the three main components [2]: the RNA polymerase II enzyme, a set of proteins called general transcription factors, and a complex of proteins called Mediator.

\section{RNA Polymerase II Enzyme-Structure and Function}

The RNA polymerase II enzyme (Figure 2A) is the structure within which the transcription process takes place. This means that DNA enters this enzyme from one direction and an mRNA product exits from another direction. Much of our work revolved around solving the complex structure of this enzyme. After solving the structure of the enzyme on its own, we also managed to solve its structure with both the DNA and the RNA present in it during the transcription process (Figure 2B).

RNA polymerase II is made up from 12 different proteins, represented by the different colors in Figure $2 \mathrm{~A}$, and built from almost 30,000 atoms. RNA polymerase II has a central channel that leads to a magnesium ion. The central channel is the place where transcription happens. A double-strand DNA enters the central channel and the two DNA strands split apart (Figure 2B). One strand bends, near the magnesium ion at the center of the enzyme. At this location, called the active center, the mRNA is synthesized, following the instructions of the bent section of the DNA strand. Finally, the hybrid DNA-mRNA structure exits the enzyme at an angle of about $90^{\circ}$ relative to the DNA entering the enzyme. 
Figure 2

The structure of the RNA polymerase II enzyme before and during transcription. (A) RNA polymerase II is made of 12 subunits (indicated in different colors) and some tens of thousands of atoms It has a central channel (white arrow) leading to a magnesium ion (pink dot). The zone where the magnesium ion is located is called the active center, since this is the region where the mRNA is synthesized from the DNA. (B) A double strand of DNA (blue and green strands) enters through the central channel of the RNA polymerase II enzyme (horizontal white arrow) and splits up toward the middle of the enzyme. The strand that controls the synthesis of the mRNA (blue) is flipped $90^{\circ}$ upwards near the active center

(upward-pointing white arrow) and a short mRNA strand is synthesized from it (short red strand at middle). This

DNA-mRNA hybrid complex exits the enzyme in a direction perpendicular to the direction from which the DNA originally entered (Image credit: Prof. Roger Kornberg).

\section{GENE}

A segment of DNA that contains information for building a protein.
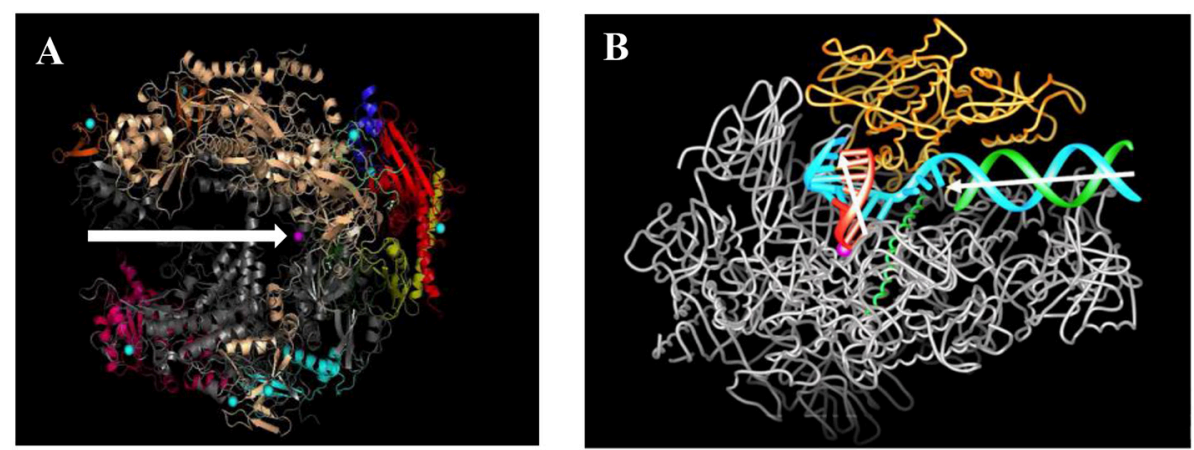

Figure 2

\section{General Transcription Factors (GTFs)-Key Components in Gene Expression}

The most important step in the process of transcription is the start of the process, called initiation. When DNA is transcribed into mRNA, it is not transcribed in its entirety. Only a specific part of it is transcribed for a specific purpose. This part of the DNA is called a gene. Each gene contains information about the production of specific proteins in our body. For the recognition of a specific gene and for deciding whether to transcribe it, the RNA polymerase II makes use of five additional molecules. These are proteins called general transcription factors (GTFs) and they come in contact with the RNA polymerase II enzyme during the transcription process (gray spheres at the bottom of Figure 3). Broadly speaking, you can think of these GTFs as components in the transcription machinery that help turn specific genes "on" or "off."

As we previously saw in Figure 2B, when the DNA moves inside the RNA polymerase II, it needs to bend to be transcribed into mRNA. However, DNA in its regular form is very stiff and not easily bent. In order to bend, it needs to be split into the individual strands, whereupon it becomes completely flexible and can bend freely. This is where the GTFs come into play: after the GTFs find the beginning of the gene in the DNA molecule, they then open the DNA and bend it near the active site of the transcription in RNA polymerase II. In this way, the GTFs begin the process of transcription.

\section{Mediator-The "Middleman" for Gene Regulation}

In the process of DNA transcription, very important decisions must be made: which gene to transcribe, in what place of the body and when to do it. This group of decisions and actions is called gene expression regulation and it is critical for the proper functioning of our body. The Mediator is a group of proteins that we discovered in 1990 [3] and it is an important part of the gene regulation mechanism: it processes all the regulatory information and delivers it to the RNA polymerase to control the decision of whether to transcribe a certain gene. 
Figure 3

RNA polymerase II transcription machinery. Bottom: General transcription factors (GTFs, gray) interact with RNA polymerase II enzyme (pol II, blue) to start DNA transcription inside the enzyme. The Mediator (pink) serves as a connecting link that delivers gene regulatory information from inside or outside the cell to the pol II enzyme. In this case, the Mediator delivers information from an activator protein (red) about the activation of a specific gene for transcription (Image credit: Prof. Roger Kornberg).

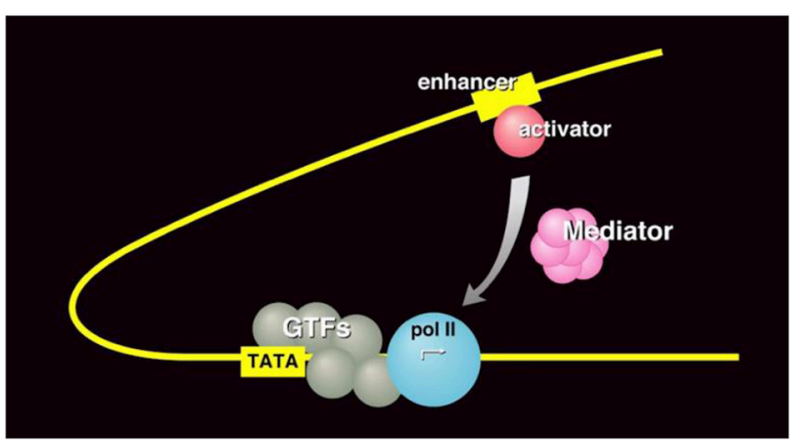

Figure 3

Figure 3 shows schematically the function of the Mediator in the transcription process: the mediator (in pink) links between a protein called an activator (in red), which influences the "turning on" of a gene for transcription, and the RNA polymerase II enzyme (in blue). In other words, the Mediator serves as the "middle man" that delivers to the RNA polymerase enzyme regulatory information about gene expression.

\section{OPEN QUESTIONS FOR THE FUTURE}

I want to pique your curiosity by briefly mentioning two unsolved problems that relate to what I have told you in this article. These topics are at the cutting edge of research in biochemistry today and we are currently working on both of them in my lab.

The first problem relates to the structure of the chromosome. At a certain stage in the division of a cell, the DNA contracts in length by a factor of about 10,000 so that the DNA, which previously occupied the whole nucleus of the cell, is condensed into the shapes of the chromosomes. What we know for sure about the structure of the chromosome can only explain the shortening of the DNA length by a factor of 5 , but not by a factor of 10,000 . So, the open question is: how does the DNA in the chromosome condense by an additional factor of 2,000 ?

The second problem relates to the Mediator and the regulation of gene expression. As you saw in Figure 3, the Mediator delivers regulatory information to the RNA polymerase II enzyme. But how is the regulatory information processed by the Mediator? How exactly is this information transmitted to the polymerase? How does the Mediator assist in the unfolding of the DNA to allow it to be transcribed? We have some ideas about what might happen and how, but these are still open problems that we are trying to solve. 


\section{TIPS FOR YOUNG MINDS}

In many ways, the questions I mentioned above are the same fundamental questions with which I started my academic endeavors. As you probably know, many scientific questions are complex and require many years of hard work to be fully addressed. Science is challenging, it requires hard work, and can be difficult and frustrating at times. But for me the occasional rewards are completely worth the struggle. If you love science and want to pursue a career as a scientist, my first advice to you is to take pleasure in the activity itself and enjoy the small, everyday activities of science. In my case, for example, these activities are experimental-mixing and dissolving different materials and making the solutions for my experiments. I personally enjoy each of these small steps and I love spending time in the laboratory.

Another important thing is to learn how to experience failure as something stimulating, something challenging-as an invitation to try again with the same high expectation of success as the last time. Every once in a while, something new and surprising happens during research. However, good scientists do not believe it straight away. First, you must make sure that it was not a mistake, so you need to think of ways to prove that you are wrong. A really good scientist thinks of extremely sophisticated ways to prove that they are wrong. When they fail to prove that they are wrong, even by ingenious experiments, then they have discovered something. These are unique and unforgettable moments in a scientist's career and they greatly outweigh the hard work that was invested in the process.

\section{REFERENCES}

1. Cramer, P., Bushnell, D. A., and Kornberg, R. D. 2001. Structural basis of transcription: RNA polymerase II at 2.8 Å resolution. Science 292:1863-76. doi: 10.1126/science.1059493

2. Boeger, H., Bushnell, D. A., Davis R., Griesenbeck, J., Lorch, Y., Strattan, J. S., et al. 2005. Structural basis of eukaryotic gene transcription. FEBS Lett. 579:899-903. doi: 10.1016/j.febslet.2004.11.027

3. Kelleher, R. J., Flanagan, P. M., and Kornberg, R. D. 1990. A novel mediator between activator proteins and the RNA polymerase II transcription apparatus. Cell 61:1209-15. doi: 10.1016/0092-8674(90)90685-8

SUBMITTED: 27 August 2020; ACCEPTED: 27 November 2020; PUBLISHED ONLINE: 07 September 2021.

EDITOR: Idan Segev, Hebrew University of Jerusalem, Israel

CITATION: Kornberg RD (2021) The Transcription of Life: From DNA to RNA. Front. Young Minds 8:599460. doi: 10.3389/frym.2020.599460 
CONFLICT OF INTEREST: The author declares that the research was conducted in the absence of any commercial or financial relationships that could be construed as a potential conflict of interest.

COPYRIGHT @ 2021 Kornberg. This is an open-access article distributed under the terms of the Creative Commons Attribution License (CC BY). The use, distribution or reproduction in other forums is permitted, provided the original author(s) and the copyright owner(s) are credited and that the original publication in this journal is cited, in accordance with accepted academic practice. No use, distribution or reproduction is permitted which does not comply with these terms.

\section{YOUNG REVIEWERS}

\section{NATAN ALTERMAN ORT JUNIOR HIGH SCHOOL, ISRAEL, AGES: 13-15}

Technological Scientific classes in "Beit Chinuch" are classes containing excellent students in the fields of science and technology. The students are curious about everything relating to science, always questioning the world around them in order to understand it better.

\section{AUTHOR}

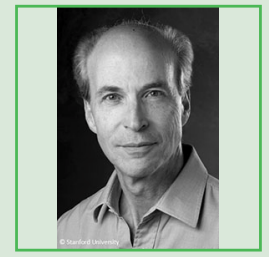

\section{ROGER D. KORNBERG}

Prof. Roger D. Kornberg, is professor of Medicine in the Department of Structural Biology at Stanford University, California U.S.A. Previously, he was a professor at Harvard Medical School. He received a Nobel Prize in chemistry in 2006 for his studies of the molecular basis of eukaryotic transcription, the process by which DNA is copied to RNA. Over the years, Prof. Kornberg has been awarded many important prizes. Kornberg received his B.S. in chemistry from Harvard University in 1967 and his Ph.D. in chemistry from Stanford University in 1972. He has served as a director of OphthaliX Inc. Since 2012 and he also serves as the Chief Scientist of Cocrystal Pharma, Inc. Prof. Kornberg is married to Prof. Yahli Lorch and they have three children, Guy, Maya, and Gil. *kornberg@astanford.edu 